\title{
An Analysis of Habitual Mode Use in the Years of Rising Oil Prices
}

\author{
Chansung Kim $\mathbb{D}^{1},{ }^{1}$ Woo-Yung Kim, ${ }^{2}$ and Jiyoung Park ${ }^{3}$ \\ ${ }^{1}$ Strategic Innovative Division, The Korea Transport Institute, Sicheong-daero 370, Sejong City, Republic of Korea \\ ${ }^{2}$ Department of Economics, Kongju National University, 56 Gongjudaehak-ro, Kongju City, Chungcheongnam-do, Republic of Korea \\ ${ }^{3}$ Smartcity Center, The Korea Transport Institute, Sicheong-daero 370, Sejong City, Republic of Korea \\ Correspondence should be addressed to Chansung Kim; cskim@koti.re.kr
}

Received 13 September 2018; Revised 11 February 2019; Accepted 20 February 2019; Published 10 March 2019

Academic Editor: Luigi Dell'Olio

Copyright (c) 2019 Chansung Kim et al. This is an open access article distributed under the Creative Commons Attribution License, which permits unrestricted use, distribution, and reproduction in any medium, provided the original work is properly cited.

\begin{abstract}
The existence of state dependence derived from panel data has played a very important role in studying employment and labor policies. This study is about state dependence of the transportation sector using retrospective panel survey data. The Ministry of Land, Infrastructure and Transport of Korea has conducted the survey to monitor changes in vehicle ownership and usage nationwide and to prepare measures when oil prices tend to rise sharply. From this data, we identify the existence of state dependence on passenger cars, public transportation, and nonmotorized modes. To do this, we estimate and analyze the dynamic random effects probit model that explains the selection of each transportation mode after controlling for the unobserved individual heterogeneity. Our results indicate that despite the rise of oil prices, behavior of habitual use (i.e., state dependence) of transportation modes is found in all three modes. The amount of state dependence of nonmotorized modes was the largest, followed by passenger cars and public transportation. From the estimated models, important policy implications can be drawn from the fact that the presence of state dependence and the importance of early habit formation are important not only in nonmotorized modes but also in public transportation. In other words, if policy makers want to encourage people to use public transportation in a new city, it suggests that a sufficient and convenient public transportation network should be built before people move to the city. Once cities are built without sufficient public transportation networks and people have become accustomed to using private cars, then it will be more difficult to change their transportation modes, requiring much more social efforts and costs.
\end{abstract}

\section{Introduction}

Let us suppose that there is a city where $50 \%$ of passengers use cars and the other $50 \%$ use public transportation. In general, such percentages can be obtained mainly from cross-sectional household travel surveys. For many years, the proportions of travel modes, which are an important indicator for policy formulation and implementation, have been estimated and utilized from such cross-sectional survey data. In addition, by analyzing the various factors influencing the choice of travel modes, policies have been attempting to reduce the share of passenger car modes and to increase the share of environment-friendly modes such as public transportation or walking. However, we can derive a richer policy implication by analyzing panel data rather than crosssectional data. In this paper we examine the decision-making and behavior of the transportation sector from a dynamic point of view using panel data.

A $50 \%$ share of public transportation has very different behavioral implications when it is interpreted from a dynamic point of view. Assume that there are two groups where one group consists of frequent mode changers and the other of less frequent changers. If all public transportation users in the first group switch to passenger cars this year from last year, and if all passenger car users switch to public transportation this year from last year, then the share of each mode of transportation will be $50 \%$. On the other hand, for the second group where the mode changes are not frequent, each mode share is again $50 \%$ even when all passengers use the same transportation modes from last year to this year. If cross-sectional data are used, both the former and the latter provide the same information of a $50 \%$ share of 
passenger cars and a $50 \%$ share of public transportation. However, the interpretation obtained from using panel data can be significantly different. In the former case, the users of the transportation system have no state dependence and in the latter case they have complete state dependence. In the latter case, past experiences determine the present and future outcomes, and the use of the same modes of transportation tends to be fixed as a habit.

The findings of state dependence using panel data will play a very important role in establishing and implementing transportation policies. First of all, if there is a state dependence, a policy that increases or decreases the use of specific modes of transportation at the beginning can be stressed because the initial use of transportation modes determines the use of transportation modes in the future. In addition, policies related to regional, infrastructural, and socioeconomic impacts will need to be considered, taking into account the importance and magnitude of impact variables of individual characteristics. However, if the state dependence does not exist on the use of transportation modes, more flexible transportation policies would be possible in order to supply and operate transportation at the right time and right place, rather than initiating initial habits.

In this study, we use retrospective transportation panel data. Korea's Ministry of Land, Infrastructure and Transport conducted a survey in the spring of 2012 to monitor changes in vehicle ownership and usage nationwide and to construct policy measures when oil prices had risen sharply since 2010. The collected data are used to identify the existence of state dependence that is customarily used for passenger cars, public transportation, and nonmotorized modes (mainly walking). And we want to analyze the factors affecting the selection of each mode after controlling for the unobserved heterogeneity of individuals. Using the data of the period when oil prices rose sharply, we are able to derive behavioral results and policy implications that are different from the existing studies based on the random effects dynamic probit model using single transportation modes. This paper is also different from previous studies in that we consider various transportation modes rather than a single mode and compare the magnitudes of state dependence among those modes in the years of rising oil prices.

\section{Literature Review}

Studies of state dependence of an individual or a firm have begun to resolve the question of whether persistence of state is due to the heterogeneous nature of individuals or firms or by past experience in the economic and social phenomena. Identifying a state dependence has been an important issue in social sciences. For example, studies in labor economics have examined and estimated the state dependence of employment barriers in the labor market, and using panel data they have analyzed the mechanisms of the persistence of nonemployment, low wages, and low labor force participation rates, especially for women [2-4].

In the transportation sector, certain studies examine the existence and influence of state dependence. Typical examples are state dependence of vehicle ownership, transportation use, and activities. In conclusion, these studies suggest that state dependence exists and should be considered in forecasting future travel demand. Studies on vehicle ownership include Bjørner et al. [5], Dargay et al. [6], and Nolan [7]. Bjørner et al. used data from over 10,000 households in Denmark from 1992 to 2001, observing vehicle availability over time. Dargay et al. estimated the dynamic random effects probit model of 10 countries from the eight waves panel data of 1994-2001 in European countries. Nolan utilized panel data from Ireland between 1995 and 2001. One of the main results of these analyses is that state dependence is the most important factor for automobile ownership, and income and the size of household are estimated as the next important factors after controlling for the unobserved heterogeneities of individuals.

Research on transportation mode use tends to be done primarily for single modes. Chartterjee used panel data from a survey of bus users before and after the construction of the Bus Rapid Transit in the Crawley and Gatwick Airport area in Southern England in 2003 [8]. Wen et al. used data from two waves to investigate motorcycle holding and utilization in Taiwan [9]. They each applied a random effects probit model and showed that the use of means was habitual and state-dependent. A study by Xiong et al. using the Puget Sound Panel data from the Seattle area of the United States showed that the values of travel time were stably estimated by income level using the Hidden Markov model [10].

Travel modes are used every day for commuting, shopping, and business activities. State dependence related research was also conducted based on observations of daily mode of transportation and activities. That is, state dependence can be identified if individual activities or schedules are examined over time. Representative studies include Ramadurai et al. and Cirillo et al. [11, 12]. Their research was possible from individual daily trips and activities data. Cirillo et al. used daily transportation panel data for six weeks. The state dependence is also analyzed for the modes and activities that are used every day [12].

Among the studies related to the effects of introducing new traffic systems or policies, studies also exist that have identified the existence of habits or inertia. Fujii et al. have studied whether there is a change in choice of modes when habitual drivers are given one-month free coupons for public transportation [13]. There is a study on the effects of the voluntary behavioral change program in Denmark before and after implementation [14]. And there is a study by González et al. that conducted the before and after stated preference/revealed preference survey of the same person when a tram was built and operated in Spain [15]. The results of these studies show that the change of modes and habitual use coexist.

\section{Data and Methodology}

3.1. Data. In this study, we use a three-year retrospective transportation panel data, data that was collected when oil 


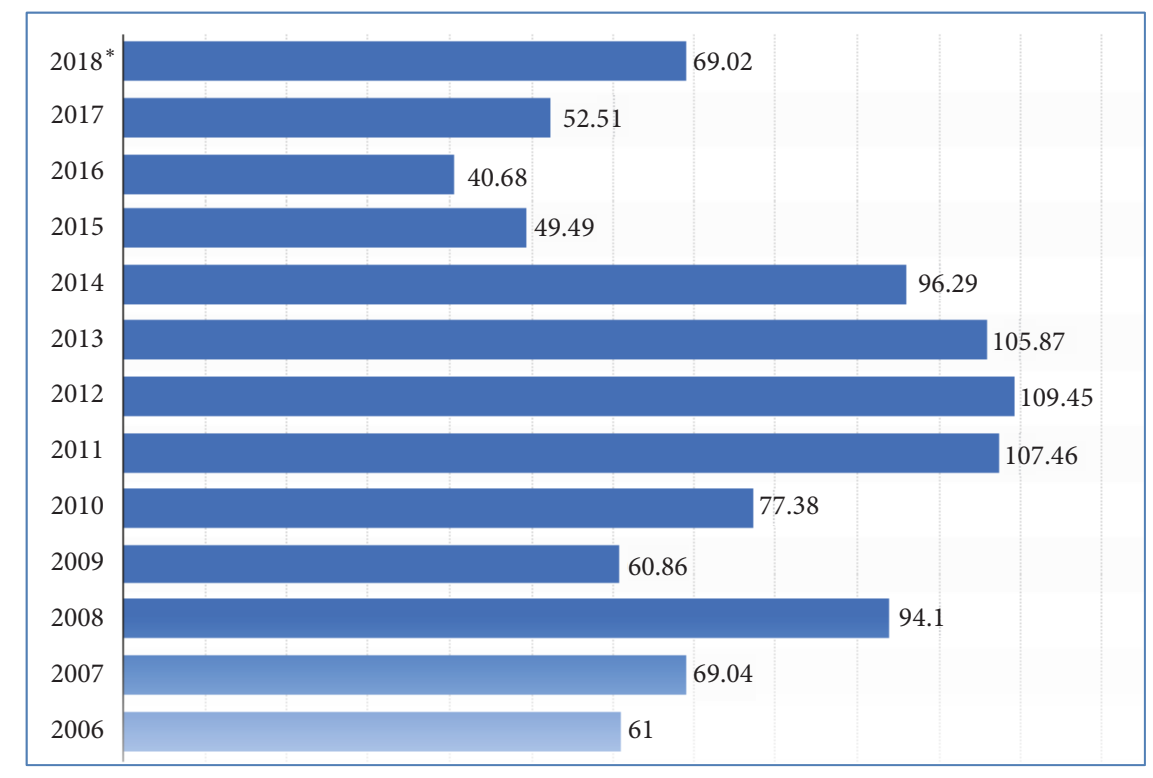

FIGURE 1: Average annual OPEC oil price (in the US dollars per barrel). Note: this figure is slightly modified from original data source [1]. Vertical line represents year and horizontal line shows oil price per barrel.

prices rose sharply. The Korean Ministry of Land, Infrastructure and Transport conducted a survey in the spring of 2012 to monitor changes in vehicle ownership and usage nationwide and to prepare transportation measures when oil prices were rising sharply since 2010. In the Statistics Portal's annual oil price information, OPEC's oil prices per barrel had risen sharply, rising to 60.86 in 2009, 77.38 in 2010, 107.46 in 2011 and 109.45 in 2012 as shown in Figure 1[1]. In Korea, there was concern that this increase would continue at the beginning of 2012, and energy use measures were required at government level. It was important to predict how changes in vehicle usage and travel patterns would change if oil prices continued to rise in the transportation sector. And, since the shift from passenger cars to public transportation was expected, the public transportation provision policy to cope with the increasing demand had to be considered.

Specifically, the Korean government surveyed 2,500 observations across the country. In order to prevent the sampling bias, a three-stage stratified sampling method was applied. First, regional allocations were investigated in line with the national census. Second, it was assigned to the sex ratio of the population. Finally, the samples were collected in proportion to the age group of the population. In other words, our sample is representative of the national census. Therefore, there is little concern that the sample will be biased. Although the Korean government collected 2,500 observations through the stratified sampling method, only 1,966 observations are used for this study, excluding observations with households (not persons) without vehicles. The reason for this is that it is more important to see the change of modes of households that have a car.

If the travel information for the same person and household is surveyed every year like the Puget Sound
Transportation Panel data, it is possible to conduct statedependent research considering various travel purposes and travel modes [16]. In this study, however, main survey questionnaires provide information on the most frequent places visited in the preceding 3 years, used travel mode, the travel time, the continuous duration of home and work, the change of home and work locations, personal characteristics, household characteristics, occupation, the number of vehicles, and income. Ommeren et al. [17-19], whose study is similar to this study, also examined the commuting distance, the modes of transportation used, and the employment status during the past five years. Schoenduwe et al. [20] summarize the usefulness of the retrospective panel data of the transportation sector including Ommeren et al. [17-19]. Compared with these previous studies, the data value of this study is considered to be sufficient. In this study, travel modes were classified into three categories: passenger cars, public transportation, and nonmotorized vehicles (pedestrians and bicycles). Sex and age were asked as individual attributes. Age was coded as follows. If the number is less than 30 , the code is $1,30 \mathrm{~s}$ is $2,40 \mathrm{~s}$ is $3,50 \mathrm{~s}$ is 4 , and if it is 60 or more, 5 is coded. For analysis, each was treated as a dummy variable. That is, if the age is less than 30 , age 20 s is 1 ; otherwise it is 0 . Ages $30 \mathrm{~s}, 40 \mathrm{~s}, 50 \mathrm{~s}$, and $60+$ were treated as dummy variables in the same manner. Regional characteristics were surveyed by the city level, and a dummy variable is created as being 1 if it is the Seoul metropolitan area and 0 otherwise.

As regards economic factors, the income level was categorized into three levels of income, low, middle, and high, but each of them was adjusted for dummy variables for analysis. The number of cars owned, the employment status, and the employment type of the employed persons were classified. Dynamic information of home and work was surveyed. Along with the duration of home and work, changes were recorded 
and coded for our study year ( $\mathrm{t}$ ), a year preceding our study year $(\mathrm{t}-1)$, and two years preceding $(\mathrm{t}-2)$. An oil dummy variable is coded as 1 when the oil price is the highest and is regarded as zero when not. Table 1 describes the variables used in this study, and Table 2 presents descriptive statistics for each variable. The survey sample was 1,966 in the year, but 5,898 observations were used for descriptive statistical analysis because three years of retrospective information is utilized.

In Table 2, the mode shares of used transportation were $57.3 \%$ for passenger cars, $31.7 \%$ for public transportation, $10.9 \%$ for nonmotorized vehicles, and 40 minutes for oneway trip to frequent destinations. Survey data gender was composed of male $(54 \%)$ and female (46\%). The average vehicle holding was 1.4 units and self-employed (self_emp) was $16.4 \%$. The proportion of residents living in the Seoul metropolitan area (Seoul_m) was $48.2 \%$ and that of the nonSeoul area (Non-Seoul_m) was $51.8 \%$. The average change of home and work place was 7 9\%.

Based on the previous literature reviews, we found that similar variables are commonly used in case studies in most transport sectors. However, some variables were used differently depending on the research purpose. First of all, in studies [5-12, 15, 17-19], age, gender, and income variables were commonly used as independent variables. In this study, we also include age, gender, and income as control variables. Regional characteristics are used in this study, which was also the case in the previous studies $[5,7,8,14]$. In the present study, the changes of work places or home locations were used, which were also found in previous studies $[8,16-$ 19]. Finally, as in this study, the number of vehicles owned appeared in the previous studies $[9,10]$.

In Tables 1 and 2, the transportation modes used in ( $t$ $2),(t-1)$, and $(t)$ years are coded with 1 or 0 binary variables depending on whether they are used or not. In other words, 1 means that the mode is used for the year, and 0 means not used. As a summary of the three years, eight combinations are possible for each mode as shown in Tables 3, 4, and 5. Providing information by dividing these transition tables by gender and age can be used to help understand this study. These binary variables are used as dependent variables of the following dynamic random effects probit model.

Two characteristics can be found from the three-year mode transition tables. First, we can find that the proportion of people who use the same modes each year is quite large. Second, the shifted proportion from passenger cars to other modes in the period between $(t-1)$ and $(t)$ rather than between $(t-2)$ and $(t-1)$ year was quite large. In addition, the frequency of public transportation mode from $(t-1)$ to $(t)$ has increased significantly. On the other hand, changes from public transportation to other modes and from nonmotorized modes to other modes were not significant. The behavioral response to oil prices appeared at a time when oil prices rose considerably.

The frequency of transition is different by gender and age. For example, it is found that males use passenger cars more, females use public transportation more, and males use nonmotorized vehicles more. By age, 30s-40s year olds for passenger cars, 20s-30s year olds for public transportation, and 60 s year olds upwards for nonmotorized vehicles were found to be highly frequent and persistent.

3.2. Methodology. A state dependence is said to exist when one's current choice depends on his or her past choices. The notion of state dependence has been widely used in economic analyses and in terms of regression analysis the state dependence occurs when a lagged dependent variable appears as one of the control variables we used. Without loss of generality, we can write a choice model as follows:

$$
\mathrm{y}_{\mathrm{it}}= \begin{cases}1 & \text { if } y_{i t}{ }^{*}=\gamma y_{i t-1}+Z_{i t} \Gamma+v_{i t}>0 \\ 0 & \text { otherwise }\end{cases}
$$

where $v_{i t}=\alpha_{i}+u_{i t}$. We assume that $u_{i t}$ is normally distributed with mean 0 and variance $\sigma_{u}^{2}$ and $\alpha_{i}$ is the individual specific time invariant term which is also normally distributed with mean 0 and variance $\sigma_{\alpha}^{2}$. In (1), we can have a spurious correlation between $y_{i t}{ }^{*}$ and $y_{i t-1}$ because the choice of the past $y_{i t-1}$ is likely to be closely related to the invisible nature $\left(\alpha_{i}\right)$ of the present choice of mode users. Heckman calls this spurious state dependence [2].

In (1), if $y_{i t-1}$ does not exist, it can be estimated as a general probit model. However, if $y_{i t-1}$ is present, the probit model does not provide consistent estimates because the initial selection is correlated with the invisible heterogeneity of individuals [21, 22]. Thus, in order to obtain unbiased estimates for (1), a two-step estimation of Heckman [2] is necessary. In this study, the random effects dynamic probit model is estimated using "redprob" command in the STATA procedure [23]. In our case, $y_{i t}$ is the current modes of transportation and $y_{i t-1}$ is the modes of transportation of the previous year. The $\gamma$ obtained from the redprob of STATA 15.0 represents the state dependence of the estimated modes of transportation.

There are many factors that cause individuals to continue to use private cars when choosing a mode of transportation. Observed or unobserved heterogeneities among individuals may have an impact on the use of private cars (or using public transport or nonmotorized modes). Therefore, in order to estimate (1) we need to consider these influencing factors, which are summarized in the vector of variables, $Z_{i t}$, in (1). Without these considerations, the influence of the state dependence could be either overestimated or underestimated. In this paper, we use as control variables the influence of travel time, geographical factors, economic factors, and social factors.

\section{Results}

4.1. Overall State Dependence Pattern. The persistence of the transportation mode can be identified by the existence of state dependence between past and present behavior after controlling for observed and unobserved heterogeneities of individuals. In (1) the state dependence is recognized by the statistical significance of the coefficient on the transportation mode of the previous year $\left(y_{i t-1}\right)$ which is $\gamma$. 
TABLE 1: Definition of used variables.

\begin{tabular}{|c|c|c|c|c|}
\hline Factor & Variable name & values & Definition & Variables \\
\hline \multirow{7}{*}{ Transport } & Car & 0,1 & $\begin{array}{c}\text { For }(\mathrm{t}-2),(\mathrm{t}-1), \mathrm{t} \text { year, if (passenger car is } \\
\text { used) } 1 \text {, otherwise } 0\end{array}$ & Dependent variable \\
\hline & Lcar & 0,1 & Lagged variable of car variable & independent variable \\
\hline & Transit & 0,1 & $\begin{array}{c}\text { For }(\mathrm{t}-2),(\mathrm{t}-1), \mathrm{t} \text { year, if (transit is used) } 1 \text {, } \\
\text { otherwise } 0\end{array}$ & Dependent variable \\
\hline & Ltransit & 0,1 & Lagged variable of transit variable & independent variable \\
\hline & Non-motor & 0,1 & $\begin{array}{l}\text { For }(\mathrm{t}-2),(\mathrm{t}-1), \mathrm{t} \text { year, if (non-motor } \\
\text { vehicle is used) } 1 \text {, otherwise } 0\end{array}$ & Dependent variable \\
\hline & Lnon-motor & 0,1 & $\begin{array}{l}\text { Lagged variable of non-motor vehicle } \\
\text { variable }\end{array}$ & independent variable \\
\hline & Time & Minutes & Travel time & independent variable \\
\hline \multirow{8}{*}{ Individual } & Female & 0,1 & If(gender $=$ female) 1 , otherwise 0 & independent variable \\
\hline & Age & $1,2,3,4,5$ & $\begin{array}{c}\text { If }(\text { age }<30) 1, \text { If }(\text { age }>=30 \& \text { age }<40) 2 \\
\text { If }(\text { age }>=40 \& \text { age }<50) 3, \text { If }(\text { age }>=50 \& \\
\text { age }<60) 4\end{array}$ & independent variable \\
\hline & & & If $($ age $>=60) 5$ & \\
\hline & Age 20s & 0,1 & If(age $<30) 1$, otherwise 0 & independent variable \\
\hline & Age 30s & 0,1 & If (age $>=30 \&$ age $<40) 1$, otherwise 0 & independent variable \\
\hline & Age 40 s & 0,1 & If $($ age $>=40 \&$ age $<50) 1$, otherwise 0 & independent variable \\
\hline & Age $50 \mathrm{~s}$ & 0,1 & If $($ age $>=50 \&$ age $<60) 1$, otherwise 0 & independent variable \\
\hline & Age $60+$ & 0,1 & If $($ age $>=60) 1$, otherwise 0 & independent variable \\
\hline Regional & Seoul_m & 0,1 & $\begin{array}{c}\text { If(residence is Seoul metropolitan area) } 1, \\
\text { otherwise 0 }\end{array}$ & independent variable \\
\hline \multirow{9}{*}{ Economic } & Self_emp & 0,1 & $\begin{array}{c}\text { If(respondent is self-employed) } 1 \\
\text { otherwise } 0\end{array}$ & independent variable \\
\hline & Vehicles & Vehicles & Number of owned vehicles & independent variable \\
\hline & & & If(household monthly income $<2000 \$$ ) 1 & \\
\hline & Income & $1,2,3$ & $\begin{array}{l}\text { If (household monthly income }>=2000 \$ \\
\& \text { household monthly income }<4000 \$) 2\end{array}$ & independent variable \\
\hline & & & If(household monthly income $>=4000 \$$ ) & \\
\hline & & & 3 & \\
\hline & Low income & 0,1 & $\begin{array}{l}\text { If(household monthly income }<2000 \$) 1 \text {, } \\
\text { otherwise } 0\end{array}$ & independent variable \\
\hline & Mid income & 0,1 & $\begin{array}{l}\text { If }(\text { household monthly income }>=2000 \$ \\
\& \text { household monthly income }<4000 \$) 1 \text {, } \\
\text { otherwise } 0\end{array}$ & independent variable \\
\hline & High income & 0,1 & $\begin{array}{l}\text { If(household monthly income }>=4000 \$ \text { ) } \\
3 \text {, otherwise } 0\end{array}$ & independent variable \\
\hline \multirow{2}{*}{ Location } & Hchg & 0,1 & $\begin{array}{c}\text { For }(\mathrm{t}-2),(\mathrm{t}-1), \mathrm{t} \text { year, if (there was the } \\
\text { change of housing location) } 1 \text {, otherwise } 0\end{array}$ & independent variable \\
\hline & Jchg & 0,1 & $\begin{array}{l}\text { For }(t-2),(t-1), t \text { year, if (there was the } \\
\text { change of job location) } 1 \text {, otherwise } 0\end{array}$ & independent variable \\
\hline Oil dummy & Oil dummy & 0,1 & if (oil price is the highest) 1 , otherwise 0 & independent variable \\
\hline
\end{tabular}

Tables 6-8 present the estimates of two different models: the first one is a simple random effects probit model and the second is the dynamic random effects probit model which takes into account a possible correlation between initial conditions and unobserved individual heterogeneity. In the second model, theta and rho represent a partial correlation and a correlation coefficient between the initial condition and unobserved individual heterogeneity, respectively. If theta and rho are 0 , it means that the initial condition is exogenous. In this case, a simple random effects probit model that does not consider initial conditions is sufficient.

In our case it is important to consider the initial condition because all of theta and rho are significantly different from 0 . From the values shown in the bottom right of Tables 6,7 , and 
TABLE 2: Descriptive statistics of used variable.

\begin{tabular}{|c|c|c|c|c|c|}
\hline Variable & Obs. & Mean & Std. Dev & Min & Max \\
\hline Car & 5,898 & 0.5732 & 0.4946 & 0 & 1 \\
\hline Transit & 5,898 & 0.3173 & 0.4655 & 0 & 1 \\
\hline Walks & 5,898 & 0.1093 & 0.3121 & 0 & 1 \\
\hline Lcar & 3,932 & 0.6119 & 0.4873 & 0 & 1 \\
\hline Ltransit & 3,932 & 0.2868 & 0.4523 & 0 & 1 \\
\hline Lwalks & 3,932 & 0.1012 & 0.3016 & 0 & 1 \\
\hline Time & 5,898 & 40.257 & 31.3602 & 1 & 180 \\
\hline Female & 5,898 & 0.4613 & 0.4985 & 0 & 1 \\
\hline Age & 5,898 & 2.8626 & 1.2725 & 1 & 5 \\
\hline Vehicles & 5,898 & 1.4120 & 0.6714 & 1 & 4 \\
\hline Seoul_m & 5,898 & 0.4821 & 0.4997 & 0 & 1 \\
\hline Income & 5,898 & 2.1931 & 0.7126 & 1 & 3 \\
\hline Self_emp & 5,898 & 0.1642 & 0.3705 & 0 & 1 \\
\hline Hchg & 5,898 & 0.0735 & 0.2611 & 0 & 1 \\
\hline Jchg & 5,898 & 0.0885 & 0.2840 & 0 & 1 \\
\hline Oil dummy & 5,898 & 0.3333 & 0.4714 & 0 & 1 \\
\hline
\end{tabular}

TABle 3: Car use status over time from $(\mathrm{t}-2)$ to $(\mathrm{t})$.

\begin{tabular}{|c|c|c|c|c|c|c|c|c|c|}
\hline$t-2$ & $\mathrm{t}-1$ & $\mathrm{t}$ & male & female & Age 20s & Age 30 s & Age 40s & Age 50s & Age $60+$ \\
\hline 1 & 1 & 1 & 504 & 337 & 62 & 209 & 280 & 203 & 87 \\
\hline 1 & 1 & 0 & 155 & 120 & 39 & 77 & 72 & 70 & 17 \\
\hline 1 & 0 & 1 & 7 & 4 & 4 & 0 & 5 & 2 & 0 \\
\hline 0 & 1 & 1 & 29 & 25 & 25 & 20 & 6 & 3 & 0 \\
\hline 0 & 0 & 1 & 35 & 34 & 26 & 20 & 16 & 5 & 2 \\
\hline 0 & 1 & 0 & 20 & 18 & 15 & 13 & 8 & 2 & 0 \\
\hline 1 & 0 & 0 & 39 & 32 & 12 & 16 & 22 & 16 & 5 \\
\hline 0 & 0 & 0 & 270 & 337 & 159 & 118 & 101 & 94 & 135 \\
\hline
\end{tabular}

TABLE 4: Transit use status over time from ( $\mathrm{t}-2)$ to $(\mathrm{t})$.

\begin{tabular}{|c|c|c|c|c|c|c|c|c|c|}
\hline$t-2$ & $\mathrm{t}-1$ & $\mathrm{t}$ & male & female & Age 20s & Age $30 \mathrm{~s}$ & Age 40s & Age 50s & Age $60+$ \\
\hline 1 & 1 & 1 & 169 & 232 & 111 & 87 & 70 & 63 & 70 \\
\hline 1 & 1 & 0 & 39 & 36 & 30 & 22 & 12 & 6 & 5 \\
\hline 1 & 0 & 1 & 17 & 19 & 15 & 12 & 7 & 2 & 0 \\
\hline 0 & 1 & 1 & 33 & 37 & 14 & 18 & 22 & 12 & 4 \\
\hline 0 & 0 & 1 & 129 & 108 & 38 & 61 & 65 & 58 & 15 \\
\hline 0 & 1 & 0 & 12 & 7 & 9 & 1 & 6 & 3 & 0 \\
\hline 1 & 0 & 0 & 26 & 25 & 25 & 16 & 5 & 3 & 2 \\
\hline 0 & 0 & 0 & 634 & 443 & 100 & 256 & 323 & 248 & 150 \\
\hline
\end{tabular}

TABLE 5: Nonmotor mode use status over time from ( $t-2)$ to $(t)$.

\begin{tabular}{|c|c|c|c|c|c|c|c|c|c|}
\hline$t-2$ & $\mathrm{t}-1$ & $\mathrm{t}$ & male & female & Age 20s & Age 30s & Age 40s & Age 50s & Age $60+$ \\
\hline 1 & 1 & 1 & 77 & 65 & 20 & 16 & 21 & 27 & 58 \\
\hline 1 & 1 & 0 & 11 & 12 & 6 & 4 & 10 & 1 & 2 \\
\hline 1 & 0 & 1 & 5 & 4 & 5 & 3 & 1 & 0 & 0 \\
\hline 0 & 1 & 1 & 8 & 11 & 7 & 3 & 2 & 4 & 3 \\
\hline 0 & 0 & 1 & 46 & 31 & 15 & 24 & 15 & 16 & 7 \\
\hline 0 & 1 & 0 & 2 & 7 & 4 & 3 & 1 & 1 & 0 \\
\hline 1 & 0 & 0 & 10 & 21 & 13 & 11 & 5 & 2 & 0 \\
\hline 0 & 0 & 0 & 900 & 756 & 272 & 409 & 455 & 344 & 176 \\
\hline
\end{tabular}


TABLE 6: Probit results of passenger car users.

\begin{tabular}{|c|c|c|c|c|c|c|c|c|}
\hline \multirow[b]{2}{*}{ Variables } & \multicolumn{4}{|c|}{ Random effects probit } & \multicolumn{4}{|c|}{ Dynamic random effects probit } \\
\hline & Coef. & S.E. & t-value & p-value & Coef. & S.E. & t-value & $\mathrm{p}$-value \\
\hline Lcar & 2.187 & 0.058 & 37.700 & 0.000 & 1.711 & 0.126 & 13.590 & 0.000 \\
\hline Female & -0.128 & 0.053 & -2.440 & 0.015 & -0.204 & 0.063 & -3.240 & 0.001 \\
\hline Age 20 s $*$ & 0.236 & 0.104 & 2.270 & 0.023 & 0.225 & 0.115 & 1.960 & 0.050 \\
\hline Age 30 s $*$ & 0.341 & 0.101 & 3.390 & 0.001 & 0.506 & 0.122 & 4.150 & 0.000 \\
\hline Age 40 s* & 0.351 & 0.101 & 3.490 & 0.000 & 0.549 & 0.127 & 4.320 & 0.000 \\
\hline Age 50 s $*$ & 0.131 & 0.103 & 1.270 & 0.205 & 0.286 & 0.123 & 2.320 & 0.020 \\
\hline Seoul_m & -0.252 & 0.054 & -4.690 & 0.000 & -0.362 & 0.069 & -5.260 & 0.000 \\
\hline Time & -0.005 & 0.001 & -6.610 & 0.000 & -0.006 & 0.001 & -6.700 & 0.000 \\
\hline Vehicles & 0.162 & 0.041 & 3.940 & 0.000 & 0.206 & 0.048 & 4.310 & 0.000 \\
\hline Self_emp & 0.207 & 0.076 & 2.720 & 0.006 & 0.323 & 0.092 & 3.530 & 0.000 \\
\hline Hchg & 0.059 & 0.100 & 0.590 & 0.554 & 0.059 & 0.105 & 0.560 & 0.573 \\
\hline Jchg & -0.027 & 0.087 & -0.310 & 0.758 & -0.020 & 0.091 & -0.220 & 0.829 \\
\hline Mid income $* *$ & 0.089 & 0.072 & 1.240 & 0.217 & 0.161 & 0.083 & 1.950 & 0.051 \\
\hline High income $* *$ & 0.148 & 0.077 & 1.910 & 0.056 & 0.231 & 0.089 & 2.580 & 0.010 \\
\hline Oil dummy & -0.559 & 0.053 & -10.470 & 0.000 & -0.580 & 0.057 & -10.240 & 0.000 \\
\hline const & -1.100 & 0.116 & -9.460 & 0.000 & -0.915 & 0.135 & -6.800 & 0.000 \\
\hline rho & & & & & 0.162 & 0.072 & 2.240 & 0.025 \\
\hline theta & & & & & 3.974 & 1.533 & 2.590 & 0.010 \\
\hline obs & \multicolumn{4}{|c|}{3932} & \multicolumn{4}{|c|}{3932} \\
\hline Log likelihood (0) & \multicolumn{4}{|c|}{-2701.45} & \multicolumn{4}{|c|}{-2701.45} \\
\hline Log likelihood (c) & \multicolumn{4}{|c|}{-1483.60} & \multicolumn{4}{|c|}{-2640.81} \\
\hline Chi-sq(df=15) & \multicolumn{4}{|c|}{2435.71} & \multicolumn{4}{|c|}{923.95} \\
\hline
\end{tabular}

Note: $*$ reference variable is age $60+* * *$ reference variable is low income.

8 , we reject the hypothesis that theta $=0$ and $r h o=0$ at least at the $95 \%$ level. Therefore, it is more appropriate to use the dynamic random effects probit model.

The random effects probit models and the dynamic random effects probit models with initial conditions show very different results. In the case of the passenger car model in Table 6, the state dependence of the probit model that does not control the initial condition is 2.187 , whereas the state dependence with the initial condition is estimated as 1.711. This implies that a simple random effects probit model overestimates the magnitude of state dependence. The dynamic random effects probit model obtains a consistent estimator by correcting the bias that occurs when treating the initial conditions exogenously. Tables 7 and 8 also show the same pattern for public transport and nonmotorized mode models.

The results of the dynamic random effects probit models of Tables 6, 7, and 8 show that past use of travel mode has a significant effect, which means that there is a strong state dependence. The estimated value for car users is 1.711, and the corresponding figures for public transportation and nonmotorized modes are 1.409 and 1.941, respectively. These values are all statistically significant, indicating that there is a high likelihood of using the same modes of transportation between past and current years. The size of state dependence among our three modes shows the order of nonmotorized modes, passenger cars, and public transportation.
As stated in the introduction, the effect of an increase in oil prices on the choice of transportation mode is analyzed. The coefficients on the oil dummy indicate that changes in oil prices affect the choice of modes of transportation. A negative value for passenger car models and a positive value for public transportation and nonmotorized models imply that people rely on cars less and rely on public transportation and nonmotorized modes more when oil prices are increasing.

4.2. Factors Determining Modes of Transportation. We now discuss factors determining the modes of transportation in more detail.

4.2.1. Passenger Car Users. Factors affecting the use of passenger cars are the lagged variable of passenger car use, gender, whether they live in the Seoul metropolitan area, the number of vehicles, travel time, self-employment status, income level, and oil price dummy variables. And these factors are statistically significant. On the other hand, the housing and job location change variables were not statistically significant.

Females are less likely to use passenger cars than males. The effect of age on the use of passenger cars is concave: the likelihood of using cars increases as people get older, but decreases after the 40s. It is found that residents of the Seoul metropolitan area rely less on the use of private cars. As the estimated value is -0.362 , the probability of using a car decreases when people reside in the Seoul metropolitan 
TABLe 7: Probit results of public transit users.

\begin{tabular}{|c|c|c|c|c|c|c|c|c|}
\hline \multirow[b]{2}{*}{ Variables } & \multicolumn{4}{|c|}{ Random effects probit } & \multicolumn{4}{|c|}{ Dynamic random effects probit } \\
\hline & Coef. & S.E. & t-value & $\mathrm{p}$-value & Coef. & S.E. & t-value & p-value \\
\hline Ltransit & 2.052 & 0.059 & 34.590 & 0.000 & 1.409 & 0.112 & 12.610 & 0.000 \\
\hline Female & 0.195 & 0.054 & 3.650 & 0.000 & 0.295 & 0.068 & 4.370 & 0.000 \\
\hline Age $20 \mathrm{~s} *$ & -0.013 & 0.103 & -0.130 & 0.897 & 0.118 & 0.122 & 0.970 & 0.330 \\
\hline Age 30 s* & -0.144 & 0.101 & -1.430 & 0.152 & -0.252 & 0.119 & -2.120 & 0.034 \\
\hline Age 40 s $*$ & -0.138 & 0.101 & -1.370 & 0.171 & -0.293 & 0.122 & -2.400 & 0.016 \\
\hline Age $50 \mathrm{~s} *$ & -0.004 & 0.104 & -0.040 & 0.969 & -0.130 & 0.124 & -1.050 & 0.294 \\
\hline Seoul_m & 0.302 & 0.054 & 5.540 & 0.000 & 0.466 & 0.076 & 6.170 & 0.000 \\
\hline Time & 0.009 & 0.001 & 11.330 & 0.000 & 0.012 & 0.001 & 10.820 & 0.000 \\
\hline Vehicles & -0.220 & 0.044 & -4.980 & 0.000 & -0.281 & 0.054 & -5.240 & 0.000 \\
\hline Self_emp & -0.162 & 0.081 & -2.010 & 0.044 & -0.305 & 0.099 & -3.080 & 0.002 \\
\hline Hchg & -0.057 & 0.103 & -0.550 & 0.579 & -0.049 & 0.111 & -0.450 & 0.656 \\
\hline Jchg & 0.035 & 0.088 & 0.400 & 0.690 & 0.020 & 0.095 & 0.210 & 0.836 \\
\hline Mid income $* *$ & 0.056 & 0.073 & 0.760 & 0.446 & 0.061 & 0.086 & 0.720 & 0.474 \\
\hline High income $* *$ & 0.063 & 0.079 & 0.790 & 0.428 & 0.049 & 0.092 & 0.530 & 0.599 \\
\hline Oil dummy & 0.417 & 0.054 & 7.760 & 0.000 & 0.443 & 0.057 & 7.730 & 0.000 \\
\hline Const & -1.627 & 0.119 & -13.670 & 0.000 & -1.575 & 0.140 & -11.270 & 0.000 \\
\hline Rho & & & & & 0.248 & 0.066 & 3.730 & 0.000 \\
\hline Theta & & & & & 4.738 & 1.508 & 3.140 & 0.002 \\
\hline Obs & \multicolumn{4}{|c|}{3932} & \multicolumn{4}{|c|}{3932} \\
\hline Log likelihood (0) & \multicolumn{4}{|c|}{-2501.62} & \multicolumn{4}{|c|}{-2819.68} \\
\hline Log likelihood (c) & \multicolumn{4}{|c|}{-1418.79} & \multicolumn{4}{|c|}{-2374.45} \\
\hline Chi-sq(df=15) & \multicolumn{4}{|c|}{2165.65} & \multicolumn{4}{|c|}{890.46} \\
\hline
\end{tabular}

Note: $*$ reference variable is age $60 . * *$ reference variable is low income.

area, which is a clear result considering the well-established public transportation infrastructure in this area. The longer the travel time, the lower the probability of using a passenger car. This is probably due to the influence of high fuel costs.

In addition, the estimated value of the number of vehicles has a positive value of 0.206 , so that the more vehicles they have, the higher the probability of using a car. The self-employed variable is more likely to use a car than the employed. Also, the higher the income level, the more likely people use passenger cars. On the other hand, changes in work or home location cannot be said to affect the use of private cars because the estimated coefficients are not statistically significant.

4.2.2. Public Transit Users. Factors affecting the use of public transportation, which are statistically significant, are the lagged variable of transit modes, gender, residence in the Seoul metropolitan area, the number of vehicles, travel time, self-employed status, and oil dummy variables. However, the level of income, and the change in home or work location were not statistically significant.

Some of the results obtained for public transportation show a different pattern from those obtained for passenger cars. For example, women are more likely to use public transportation than men. Middle aged people use public transportation less and young and older people rely on public transportation more. These results are consistent with our expectation.

People living in the Seoul metropolitan area have a high probability of using public transportation. This is again a clear result because of the well-established public transportation infrastructure of the Seoul metropolitan area compared to the provincial regions. The longer the travel time, the higher the probability of using public transportation. This is the opposite pattern to the use of passenger cars. The number of vehicles and the self-employed variables tend to decrease the probability of using public transportation, which is also the opposite to the case of passenger cars. Finally, changes in income level or location of work or home cannot be said to affect the sustainable use of public transportation because the estimated coefficients are not statistically significant.

4.2.3. Nonmotorized Users. The number of statistically significant variables on the use of nonmotorized modes is less than those for passenger cars and public transportation. The lagged variable of nonmotorized modes, age, travel time, selfemployed status, and income level and oil dummy variables are statistically significant. The other variables are found to be statistically insignificant.

Unlike the previous cases, gender does not affect the use of nonmotorized modes. People aged 30 s and 40 s have a lower probability of using nonmotorized modes than the rest of the age groups. Finally, the probability of using 
TABLE 8: Probit results of nonmotorized vehicle users.

\begin{tabular}{|c|c|c|c|c|c|c|c|c|}
\hline \multirow[b]{2}{*}{ Variables } & \multicolumn{4}{|c|}{ Random effects probit } & \multicolumn{4}{|c|}{ Dynamic random effects probit } \\
\hline & Coef. & S.E. & t-value & $\mathrm{p}$-value & Coef. & S.E. & t-value & $\mathrm{p}$-value \\
\hline Lnon-motor & 2.710 & 0.091 & 29.820 & 0.000 & 1.941 & 0.177 & 10.960 & 0.000 \\
\hline Female & -0.073 & 0.077 & -0.950 & 0.343 & -0.068 & 0.098 & -0.690 & 0.490 \\
\hline Age 20 s $*$ & -0.103 & 0.134 & -0.770 & 0.442 & -0.216 & 0.170 & -1.270 & 0.203 \\
\hline Age 30 s $*$ & -0.157 & 0.131 & -1.200 & 0.230 & -0.388 & 0.178 & -2.180 & 0.029 \\
\hline Age $40 s *$ & -0.311 & 0.136 & -2.280 & 0.022 & -0.549 & 0.185 & -2.970 & 0.003 \\
\hline Age $50 \mathrm{~s} *$ & -0.032 & 0.135 & -0.230 & 0.815 & -0.206 & 0.180 & -1.140 & 0.252 \\
\hline Seoul_m & -0.053 & 0.078 & -0.670 & 0.502 & -0.094 & 0.103 & -0.910 & 0.364 \\
\hline Time & -0.010 & 0.002 & -6.460 & 0.000 & -0.016 & 0.003 & -5.580 & 0.000 \\
\hline Vehicles & 0.049 & 0.057 & 0.850 & 0.393 & 0.029 & 0.075 & 0.380 & 0.702 \\
\hline Self_emp & -0.176 & 0.115 & -1.520 & 0.128 & -0.283 & 0.155 & -1.830 & 0.067 \\
\hline Hchg & -0.014 & 0.148 & -0.100 & 0.923 & -0.087 & 0.174 & -0.500 & 0.615 \\
\hline Jchg & 0.049 & 0.123 & 0.400 & 0.690 & 0.026 & 0.143 & 0.180 & 0.855 \\
\hline Mid income $* *$ & -0.188 & 0.096 & -1.970 & 0.049 & -0.369 & 0.133 & -2.780 & 0.005 \\
\hline High income $* *$ & -0.339 & 0.109 & -3.120 & 0.002 & -0.602 & 0.163 & -3.700 & 0.000 \\
\hline Oil dummy & 0.418 & 0.079 & 5.310 & 0.000 & 0.490 & 0.092 & 5.340 & 0.000 \\
\hline const & -1.418 & 0.154 & -9.190 & 0.000 & -1.118 & 0.204 & -5.470 & 0.000 \\
\hline rho & & & & & 0.391 & 0.119 & 3.280 & 0.001 \\
\hline theta & & & & & 2.245 & 0.699 & 3.210 & 0.001 \\
\hline obs & \multicolumn{4}{|c|}{3932} & \multicolumn{4}{|c|}{3932} \\
\hline Log likelihood (0) & \multicolumn{4}{|c|}{-1378.06} & \multicolumn{4}{|c|}{-1384.24} \\
\hline Log likelihood (c) & \multicolumn{4}{|c|}{-635.93} & \multicolumn{4}{|c|}{-1185.73} \\
\hline Chi-sq(df=15) & \multicolumn{4}{|c|}{1484.27} & \multicolumn{4}{|c|}{397.01} \\
\hline
\end{tabular}

Note: $*$ reference variable is age $60+. * *$ reference variable is low income.

TABLE 9: Estimation of state dependence of passenger car users.

\begin{tabular}{lcccc}
\hline & $(1)$ & $(2)$ & $(3)$ & $(4)$ \\
\hline Variables & $\begin{array}{l}\text { The probability that a person using a } \\
\text { car }(\mathrm{t}-1) \text { year will use the car }(\mathrm{t}) \text { year }\end{array}$ & $\begin{array}{c}\text { The probability that a person who did not } \\
\text { use a car }(\mathrm{t}-1) \text { year will use the car }(\mathrm{t}) \text { year }\end{array}$ & $\begin{array}{c}\text { Difference } \\
(1)-(2)\end{array}$ & $\begin{array}{c}\text { Estimates of State } \\
\text { Dependence }\end{array}$ \\
\hline Male & 0.913 & 0.378 & 0.535 & 0.569 \\
\hline Female & 0.911 & 0.342 & 0.538 & 1.750 \\
\hline Seoul metro & 0.898 & 0.360 & 0.569 & 1.626 \\
\hline Non Seoul metro & 0.928 & 0.359 & 1.827 \\
\hline
\end{tabular}

nonmotorized modes decreases as travel time and income increase.

4.3. The Size of State Dependence. The previous analysis has examined the existence of state dependence and the factors affecting the choice of transportation modes. However, equally important is the prediction of state dependence by modes. It will be also interesting to compare the magnitudes of state dependence with similar characteristics. Here, we present the probability of using a car in year $(\mathrm{t})$ if everyone used a car in year ( $t-1)$, not the probability that a person using a car in year ( $t-1)$ will use a car in year $(t)$. That is, we present an average probability of using a car conditional on that everyone used a car in the previous year. The same is true for public transportation and nonmotorized modes.
In the literature review, Bjørner et al. have identified the magnitude of state dependence of vehicle ownership [5]. Our study also predicts these intensities, which are estimated by Wooldridge's method [24]. As shown in Tables 6-8, the coefficients of the lagged dependent variables are shown in the order of nonmotorized modes, passenger cars, and public transportation. This pattern is also observed in Tables 9-11. However, an interesting fact is that marginal effects of the state dependence, which is column (3) in Tables 9-11, are the largest for car users. People who use cars in the previous year are about 55\% more likely to use cars in the next period than those who do not. However, in the case of nonmotorized modes, the marginal effect is generally less than $40 \%$. The reason for this phenomenon is that the marginal effect is estimated to be small for nonmotorized modes because the sample mean of nonmotorized modes is absolutely low $(10 \%$ 
TABLE 10: Estimation of state dependence of transit users.

\begin{tabular}{lcccc}
\hline & & $(1)$ & $(2)$ & $(3)$ \\
Variables & $\begin{array}{c}\text { The probability that a person using a } \\
\text { transit }(\mathrm{t}-1) \text { year will use the transit }(\mathrm{t}) \text { year }\end{array}$ & $\begin{array}{c}\text { The probability that a person who did not use } \\
\text { a transit }(\mathrm{t}-1) \text { year will use the transit }(\mathrm{t}) \text { year }\end{array}$ & $\begin{array}{c}\text { Difference } \\
(1)-(2)\end{array}$ & $\begin{array}{c}\text { Estimates of State } \\
\text { Dependence }\end{array}$ \\
\hline Male & 0.654 & 0.169 & 0.485 & 1.355 \\
\hline Female & 0.759 & 0.225 & 0.534 & 1.460 \\
\hline Seoul metro & 0.751 & 0.262 & 0.489 & 1.313 \\
\hline Non Seoul metro & 0.683 & 0.138 & 0.545 & 1.563 \\
\hline
\end{tabular}

TABLE 11: Estimation of state dependence of nonmotorized users.

\begin{tabular}{lcccc}
\hline & $(1)$ & $(2)$ & $(3)$ & $(4)$ \\
\hline Variables & $\begin{array}{c}\text { The probability that a non-motor using a } \\
\text { car (t-1) year will use the non-motor (t) year }\end{array}$ & $\begin{array}{c}\text { The probability that a person who did not use a } \\
\text { non-motor (t-1) year will use the non-motor (t) } \\
\text { year }\end{array}$ & $\begin{array}{c}\text { Difference } \\
(1)-(2)\end{array}$ & $\begin{array}{c}\text { Estimates of } \\
\text { State } \\
\text { Dependence }\end{array}$ \\
\hline Male & 0.462 & 0.015 & 0.447 & 2.083 \\
\hline Female & 0.367 & 0.015 & 0.352 & 1.836 \\
\hline Seoul metro & 0.383 & 0.014 & 0.369 & 1.911 \\
\hline $\begin{array}{l}\text { Non Seoul } \\
\text { metro }\end{array}$ & 0.414 & 0.015 & 0.399 \\
\hline
\end{tabular}

in Table 2). On the other hand, the state dependence of a passenger car is similar to the state dependence of a passenger car estimated by Bjørner et al. [5]

Comparing the state dependence of males and females, females are more dependent on cars and public transport than males, but they are less dependent on nonmotorized modes. The marginal effects show the same pattern. On the other hand, the residents of non-Seoul metropolitan area have a greater state dependence than the residents of Seoul metropolitan area in all modes of transportation. This may be true because it is difficult for the non-Metropolitan area residents to switch to other modes of transportation due to the lack of various modes of transportation.

Finally, we note that people have the highest state dependence (coefficient on lagged variable) on nonmotorized modes, but the probability of using nonmotorized modes is as low as $10 \%$ of total transportation modes. Nevertheless, Table 11 shows that $46 \%$ of males and $36 \%$ of females would use nonmotorized modes if they had used them in the previous year. These figures are much higher than the actual $10 \%$. This indicates that the effect of state dependence is very large for nonmotorized modes.

4.4. Estimation Results of Two-Period Lag Dependent Variables. In this section we extend our analysis to a model which includes two-period lag dependent variables. An example can be found in a recent paper by Xiong, Yang, and Zhang [16] who examined car ownership using a high-order Markov model. However, unlike their method which uses transition probabilities based on multinomial logit, we estimate a dynamic probit model which assumes that the errors are normally distributed. Our extended model can be expressed as follows:

$$
\mathrm{y}_{\mathrm{it}}= \begin{cases}1 & \text { if } y_{i t}^{*}=\gamma_{1} y_{i t-1}+\gamma_{2} y_{i t-2}+Z_{i t} \Gamma+v_{i t}>0 \\ 0 & \text { otherwise }\end{cases}
$$

where $v_{i t}=\alpha_{i}+u_{i t}$. Like before, we assume that $u_{i t}$ is normally distributed with mean 0 and variance $\sigma_{u}^{2}$. To estimate (2), we adopt two approaches. The first method is to estimate (2) by a simple probit. Note that we have 3-year panel data so that we only have a single observation for each person in the specification of (2). The second method is to correct for the initial condition problem by using the two-step methods proposed by Arulampalam et al. [25], Dorsett [26], and Phimister et al. [27]. Because "redprob" command in the STATA procedure only allows one-period lag dependent variable, we need to use the two-step method to estimate (2).

The two-step method can be described as follows. First, we estimate the probit equation for period 1; i.e., $\mathrm{t}=1$.

$$
\mathrm{y}_{\mathrm{i} 1}= \begin{cases}1 & \text { if } y_{i 1}{ }^{*}=Q_{i} \lambda+\eta_{i}>0 \\ 0 & \text { otherwise }\end{cases}
$$

We assume that $\alpha_{i}$ and $\eta_{i}$ are correlated with the correlation coefficient $\rho$. Then, (2) can be written as

$$
\begin{aligned}
& \mathrm{y}_{\mathrm{it}} \\
& = \begin{cases}1 & \text { if } y_{i t}{ }^{*}=\gamma_{1} y_{i t-1}+\gamma_{2} y_{i t-2}+Z_{i t} \Gamma+\rho \eta_{i}+\varepsilon_{i t}>0 \\
0 & \text { otherwise }\end{cases}
\end{aligned}
$$


It can be shown that $\mathrm{E}\left[\eta_{i} \mid \mathrm{y}_{\mathrm{il}}\right]=\left(\varphi\left(Q_{i} \lambda\right) / \Phi\left(Q_{i} \lambda\right)[1-\right.$ $\left.\left.\Phi\left(Q_{i} \lambda\right)\right]\right)\left[y_{i 1}-\Phi\left(Q_{i} \lambda\right)\right]$, where $\varphi$ and $\Phi$ are normal and cumulative normal densities, respectively. By substituting $\mathrm{E}\left[\eta_{i} \mid \mathrm{y}_{\mathrm{i} 1}\right]$ for $\eta_{i}$ in (4) and estimating it using probit, we can obtain consistent estimates for $\gamma_{1}$ and $\gamma_{2}$.

The estimation results are presented in Table 12. Note that regardless of controlling for initial conditions, the coefficients on $y_{i t-1}$ are much larger than the coefficients on $y_{i t-2}$. Also, when we control for the initial condition, the coefficients on $y_{i t-2}$ become all statistically insignificant even at the $10 \%$ level. Therefore, our previous results obtained with only one-period lag dependent variable can be regarded as quite reliable. In fact, the state dependence $(\gamma)$ shown in Tables $6-8$ is not substantially different from the state dependence $\left(\gamma_{1}\right)$ appeared in Table 12. However, due to the short-period panel (3 years), we are able to control for individual heterogeneities, so the results presented in Table 12 have to be interpreted with a caution.

\section{Conclusions}

In previous studies using cross-sectional data, the most important factors influencing the use of transportation were generally time and cost. However, in the present study using panel data, the state dependence on mode use is found to be a very important factor. In fact, all of the lagged dependent variables are statistically significant at the $99 \%$ level. The existence of state dependence found in this study represents familiarity habits because we have taken into account the unobserved individual heterogeneity in estimation.

The main purpose of this study was to identify the existence of state dependence by considering the problem of initial conditions in the choice of transportation modes. In other words, the analysis of the decision of the individual to select the transportation mode was divided into two parts: the random effects probit model which does not consider the initial condition problem and the dynamic model which takes into account the initial condition problem. It turns out that the initial condition problem is important so that the coefficient of the lagged dependent variable in a simply random effects model is overestimated. Therefore, the state dependence obtained without considering the initial condition exaggerates the true dependence of travel modes.

The magnitude of state dependence of the transportation mode appears in the order of nonmotorized, passenger cars, and public transportations, and these results are independent of gender or metropolitan area. Interestingly, however, an increase in the probability of using the same mode of transportation due to state dependence is the largest for cars and least for nonmotorized vehicles. The reason is that the marginal effect of state dependence is estimated to be small because the absolute sample proportion of using nonmotorized modes is low.

Some factors influencing the use of public transportation and passenger cars work in the opposition direction. At the time of rises in oil price, people used all three methods habitually in the same pattern. However, the effect of the highest oil prices was different depending on travel modes. Negative value for passenger cars, positive values for public transportation, and nonmotorized vehicles show a reduction in the persistence of passenger cars and an increase in the persistence of public transportation and nonmotorized modes.

Based on the results of this study, some policy implications can be derived. Without a state dependence, people's habits will not have a significant impact on the choice of transportation modes, so the policy intending to change people's transportation modes will be more likely to succeed. For example, when policies to increase the use of walking or bicycling are implemented, those policies will be more successful if the state dependence of a travel mode is weak. However, our study shows that past transportation mode has a great impact on the current transportation decision. This implies a considerable state dependence in the choice of transportation mode, so the policies relying on campaigning on walking or cycling are unlikely to succeed.

A high state dependence means that a person who chooses a mode of transportation before is more likely to choose the same mode of transportation thereafter. Thus, if one tries to change a person's transportation mode, it will take more effort and costs when the person has a strong state dependence than when the person has a weak state dependence. In the former case, policy makers should pay more attention to determining the initial modes of transportation. For example, if policy makers want to encourage people to use public transportation in a new city, they need to build a sufficient and convenient public transportation network before people move to the city. Once cities are built without sufficient public transportation networks and with people having become accustomed to using private cars, then it will be more difficult to change their transportation modes and also much more social efforts and costs will be required.

\section{Data Availability}

The data used to support the findings of this study are available from the corresponding author upon request.

\section{Conflicts of Interest}

The authors declare that there are no conflicts of interest regarding the publication of this article.

\section{Acknowledgments}

This research was funded by The Ministry of Land, Infrastructure and Transport (MOLIT) of Korea. The authors thank MOLIT for providing the opportunity to conduct this research. 
TABLE 12: Estimation results of probit equations with two-period lag dependent variables.

\begin{tabular}{|c|c|c|c|c|c|c|}
\hline & \multicolumn{3}{|c|}{$\begin{array}{c}\text { Probit Estimates } \\
\text { Without Controlling Initial Conditions }\end{array}$} & \multicolumn{3}{|c|}{$\begin{array}{c}\text { Probit Estimates } \\
\text { With Controlling Initial Conditions }\end{array}$} \\
\hline & Car & Transit & Non-motor & Car & Transit & Non-motor \\
\hline \multirow{2}{*}{ Lcar } & $1.574 * *$ & & & $1.568 * *$ & & \\
\hline & $(0.116)$ & & & $(0.116)$ & & \\
\hline \multirow{2}{*}{ LLcar } & $0.296 *$ & & & -0.460 & & \\
\hline & $(0.116)$ & & & $(0.674)$ & & \\
\hline \multirow{2}{*}{ Ltransit } & & $1.402 * *$ & & & $1.374 * *$ & \\
\hline & & $(0.113)$ & & & $(0.114)$ & \\
\hline \multirow{2}{*}{ LLtransit } & & $0.421 * *$ & & & -0.461 & \\
\hline & & $(0.115)$ & & & $(0.365)$ & \\
\hline \multirow{2}{*}{ Lnon-motor } & & & $2.004 * *$ & & & $1.996 * *$ \\
\hline & & & $(0.190)$ & & & $(0.190)$ \\
\hline \multirow{2}{*}{ LLnon-motor } & & & $0.720 * *$ & & & 0.309 \\
\hline & & & $(0.188)$ & & & $(0.555)$ \\
\hline \multirow{2}{*}{ Female } & $-0.118 *$ & $0.204 * *$ & -0.155 & $-0.196 * *$ & $0.291 * *$ & -0.150 \\
\hline & $(0.069)$ & $(0.070)$ & $(0.099)$ & $(0.097)$ & $(0.078)$ & $(0.099)$ \\
\hline \multirow{2}{*}{ Age $20 s *$} & 0.171 & -0.018 & -0.054 & 0.098 & 0.141 & -0.085 \\
\hline & $(0.140)$ & $(0.137)$ & $(0.181)$ & $(0.153)$ & $(0.150)$ & $(0.184)$ \\
\hline \multirow{2}{*}{ Age 30 s $*$} & 0.188 & -0.052 & 0.046 & $0.330 *$ & -0.113 & -0.010 \\
\hline & $(0.132)$ & $(0.131)$ & $(0.172)$ & $(0.181)$ & $(0.133)$ & $(0.186)$ \\
\hline \multirow{2}{*}{ Age $40 s *$} & $0.316 * *$ & -0.089 & -0.241 & $0.524 * *$ & -0.234 & -0.299 \\
\hline & $(0.132)$ & $(0.132)$ & $(0.180)$ & $(0.225)$ & $(0.144)$ & $(0.194)$ \\
\hline \multirow{2}{*}{ Age 50 s $*$} & 0.015 & 0.099 & 0.087 & 0.191 & -0.014 & 0.034 \\
\hline & $(0.135)$ & $(0.135)$ & $(0.180)$ & $(0.205)$ & $(0.142)$ & $(0.191)$ \\
\hline \multirow{2}{*}{ Seoul_m } & $-0.237 * *$ & $0.285 * *$ & -0.073 & $-0.350 * *$ & $0.445 * *$ & -0.080 \\
\hline & $(0.070)$ & $(0.071)$ & $(0.101)$ & $(0.122)$ & $(0.095)$ & $(0.101)$ \\
\hline \multirow{2}{*}{ Time } & $-0.005 * *$ & $0.009 * *$ & $-0.011 * *$ & $-0.006 * *$ & $0.011 * *$ & $-0.012 * *$ \\
\hline & $(0.001)$ & $(0.001)$ & $(0.002)$ & $(0.001)$ & $(0.001)$ & $(0.002)$ \\
\hline \multirow{2}{*}{ Vehicles } & $0.188 * *$ & $-0.257 * *$ & 0.071 & $0.225 * *$ & $-0.288 * *$ & 0.062 \\
\hline & $(0.053)$ & $(0.058)$ & $(0.073)$ & $(0.062)$ & $(0.059)$ & $(0.074)$ \\
\hline \multirow{2}{*}{ Self_emp } & $0.190 * *$ & -0.110 & -0.176 & $0.315 * *$ & $-0.236 * *$ & -0.193 \\
\hline & $(0.096)$ & $(0.102)$ & $(0.146)$ & $(0.146)$ & $(0.114)$ & $(0.148)$ \\
\hline \multirow{2}{*}{ Hchg } & 0.033 & -0.069 & 0.008 & 0.035 & -0.086 & 0.006 \\
\hline & $(0.133)$ & $(0.137)$ & $(0.180)$ & $(0.133)$ & $(0.137)$ & $(0.181)$ \\
\hline \multirow{2}{*}{ Jchg } & $-0.249 * *$ & 0.122 & $0.318 * *$ & $-0.259 * *$ & 0.125 & $0.316 * *$ \\
\hline & $(0.111)$ & $(0.112)$ & $(0.144)$ & $(0.111)$ & $(0.112)$ & $(0.144)$ \\
\hline \multirow{2}{*}{ Midincome } & 0.031 & 0.125 & -0.154 & 0.098 & 0.118 & -0.190 \\
\hline & $(0.095)$ & $(0.096)$ & $(0.124)$ & $(0.112)$ & $(0.096)$ & $(0.132)$ \\
\hline \multirow{2}{*}{ Highincome } & $0.172 *$ & 0.061 & $-0.348 * *$ & $0.256 * *$ & 0.039 & $-0.388 * *$ \\
\hline & $(0.102)$ & $(0.104)$ & $(0.141)$ & $(0.126)$ & $(0.104)$ & $(0.149)$ \\
\hline \multirow{2}{*}{ Cons } & $-1.342 * *$ & $-1.212 * *$ & $-1.108 * *$ & $-1.007 * *$ & $-1.003 * *$ & $-0.943 * *$ \\
\hline & $(0.153)$ & $(0.150)$ & $(0.197)$ & $(0.331)$ & $(0.171)$ & $(0.287)$ \\
\hline $\mathrm{E}\left[n . \mid \mathrm{v}_{\mathrm{u}}\right]$ & - & - & & 0.461 & $0.551 * *$ & 0.230 \\
\hline $\mathrm{E}\left[\eta_{i} \mid \mathrm{y}_{\mathrm{i} 1}\right]$ & - & - & - & $(0.405)$ & $(0.217)$ & $(0.292)$ \\
\hline Log-likelihood & -896.04 & -853.18 & -389.85 & -895.39 & -849.92 & -389.54 \\
\hline Obs & 1,966 & 1,966 & 1,966 & 1,966 & 1,966 & 1,966 \\
\hline
\end{tabular}

Note: the numbers in the parentheses are standard errors. $* *$ and $*$ denote significance at the $5 \%$ and $10 \%$ level, respectively. 


\section{References}

[1] https://www.statista.com/statistics/262858/change-in-opec-crudeoil-prices-since-1960/.

[2] J. J. Heckman, "Heterogeneity and state dependence," in Studies in Labor Markets, S. Rosen, Ed., pp. 91-139, University of Chicago Press, 1981.

[3] M. B. Stewart and J. K. Swaffield, "Low pay dynamics and transition probabilities," Economica, vol. 66, no. 261, pp. 23-42, 1999.

[4] L. Cappellari and S. P. Jenkins, "Who stays poor? Who becomes poor? Evidence from the British household panel survey," Economic Journal, vol. 112, no. 478, pp. C60-C67, 2002.

[5] T. B. Bjørner and S. Leth-Petersen, "Dynamic models of car ownership at the household level," International Journal of Transport Economics, vol. 32, no. 1, pp. 57-75, 2005.

[6] J. Dargay, L. Hivert, and D. Legros, “The dynamics of car availability in EU countries: a comparison based on the European household panel survey," IATSS Research, vol. 32, no. 2, pp. 4455, 2008.

[7] A. Nolan, "A dynamic analysis of household car ownership," Transportation Research Part A: Policy and Practice, vol. 44, no. 6, pp. 446-455, 2010.

[8] K. Chatterjee, "Modelling the dynamics of bus use in a changing travel environment using panel data," Transportation, vol. 38, no. 3, pp. 487-509, 2011.

[9] C.-H. Wen, Y.-C. Chiou, and W.-L. Huang, "A dynamic analysis of motorcycle ownership and usage: a panel data modeling approach," Accident Analysis \& Prevention, vol. 49, pp. 193-202, 2012.

[10] C. Xiong, X. Chen, X. He, W. Guo, and L. Zhang, "The analysis of dynamic travel mode choice: a heterogeneous hidden Markov approach,” Transportation, vol. 42, no. 6, pp. 985-1002, 2015.

[11] G. Ramadurai and K. K. Srinivasan, "Dynamics and variability in within-day mode choice decisions: role of state dependence, habit persistence, and unobserved heterogeneity," Transportation Research Record, vol. 1977, no. 1, pp. 43-52, 2006.

[12] C. Cirillo and K. W. Axhausen, "Dynamic model of activity-type choice and scheduling," Transportation, vol. 37, no. 1, pp. 15-38, 2010.

[13] S. Fujii and R. Kitamura, "What does a one-month free bus ticket do to habitual drivers? An experimental analysis of habit and attitude change," Transportation, vol. 30, no. 1, pp. 81-95, 2003.

[14] I. Meloni, B. Sanjust, E. Sottile, and E. Cherchi, "Propensity for voluntary travel behavior changes: an experimental analysis," Procedia - Social and Behavioral Sciences, vol. 87, pp. 31-43, 2013.

[15] R. M. González, Á. S. Marrero, and E. Cherchi, "Testing for inertia effect when a new tram is implemented," Transportation Research Part A: Policy and Practice, vol. 98, pp. 150-159, 2017.

[16] C. Xiong, D. Yang, and L. Zhang, "A high-order hidden markov model and its applications for dynamic car ownership analysis," Transportation Science, vol. 52, no. 6, pp. 1365-1375, 2018.

[17] J. N. Ommeren, P. Rietveld, and P. Nijkamp, "Commuting: in search of jobs and residences," Journal of Urban Economics, vol. 42, no. 3, pp. 402-421, 1997.

[18] J. N. Ommeren, G. J. Van Den Berg, and C. Gorter, "Estimating the marginal willingness to pay for commuting," Journal of Regional Science, vol. 40, no. 3, pp. 541-563, 2000.

[19] J. N. Ommeren, P. Rietveld, and P. Nijkamp, "Job mobility, residential mobility and commuting: a theoretical analysis using search theory," Annals of Regional Science, vol. 34, no. 2, pp. 213 $232,2000$.

[20] R. Schoenduwe, M. G. Mueller, A. Peters, and M. Lanzendorf, "Analysing mobility biographies with the life course calendar: a retrospective survey methodology for longitudinal data collection," Journal of Transport Geography, vol. 42, pp. 98-109, 2015.

[21] D. R. Hyslop, "State dependence, serial correlation and heterogeneity in intertemporal labor force participation of married women," Econometrica, vol. 67, no. 6, pp. 1255-1294, 1999.

[22] C. Hsiao, Analysis of Panel Data, MIT Press, Cambridge, Mass, USA, 1986.

[23] M. B. Stewart, -Redprob- a Stata Program for the Heckman Estimator of the Random Effects Dynamic Probit Model, mimeo, University of Warwick, 2006.

[24] J. M. Wooldridge, "Simple solutions to the initial conditions problem in dynamic, nonlinear panel data models with unobserved heterogeneity," Journal of Applied Econometrics, vol. 20, no. 1, pp. 39-54, 2005.

[25] W. Arulampalam, A. Booth, and M. Taylor, "Unemployment persistence," Oxford Economic Papers, vol. 52, no. 1, pp. 24-50, 2000.

[26] R. Dorsett, "An econometric analysis of smoking prevalence among lone mothers," Journal of Health Economics, vol. 18, no. 4, pp. 429-441, 1999.

[27] E. Phimister, E. Vera-Toscano, and A. Weersink, "Female participation and labor market attachment in rural Canada," American Journal of Agricultural Economics, vol. 84, no. 1, pp. 210-221, 2002. 


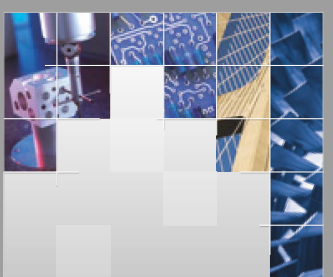

\section{Enfincering}
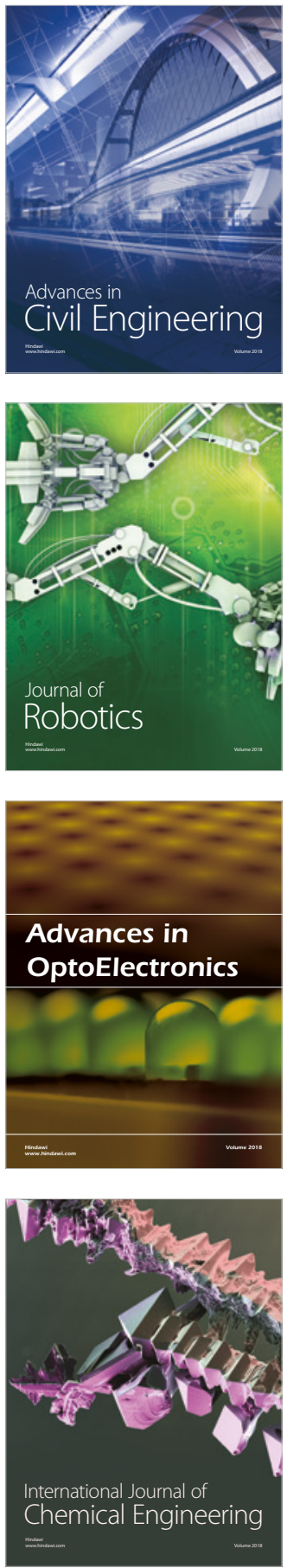

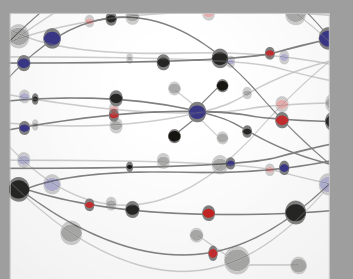

\section{Rotating \\ Machinery}

The Scientific World Journal

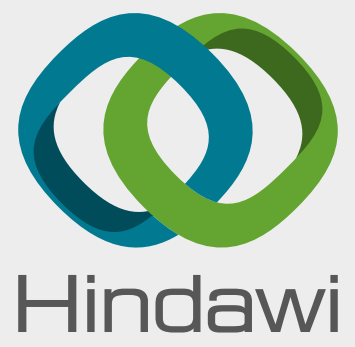

Submit your manuscripts at

www.hindawi.com
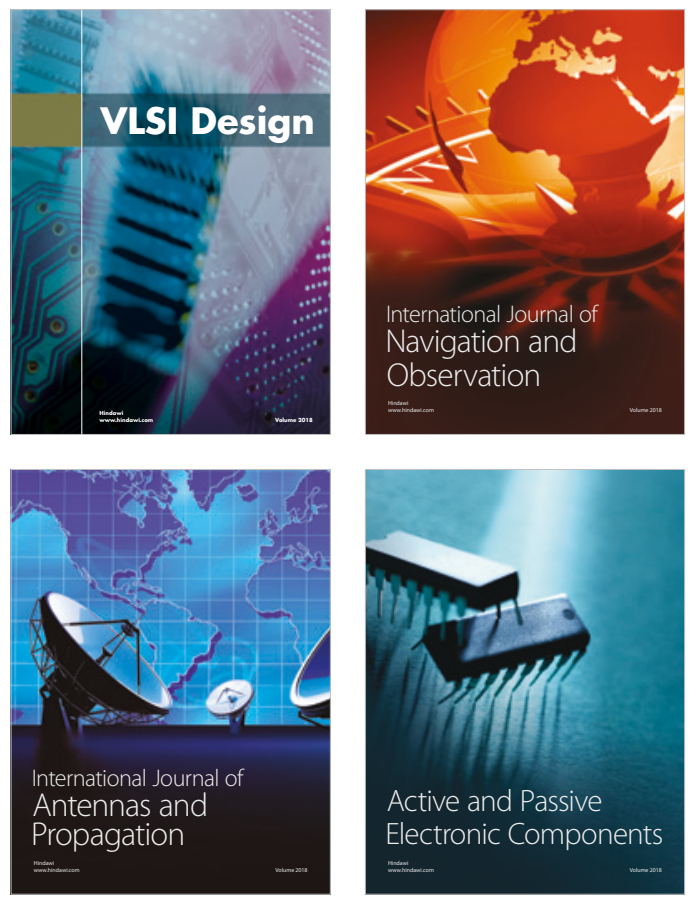
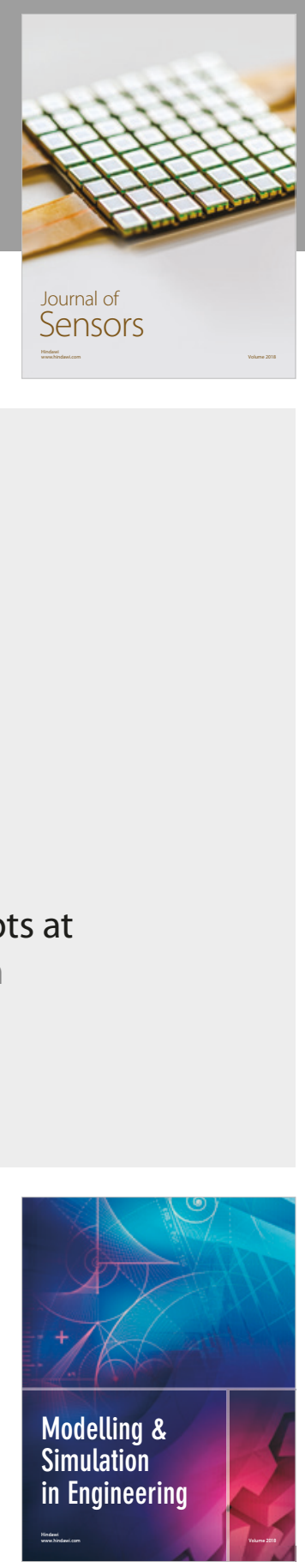

\section{Advances \\ Multimedia}
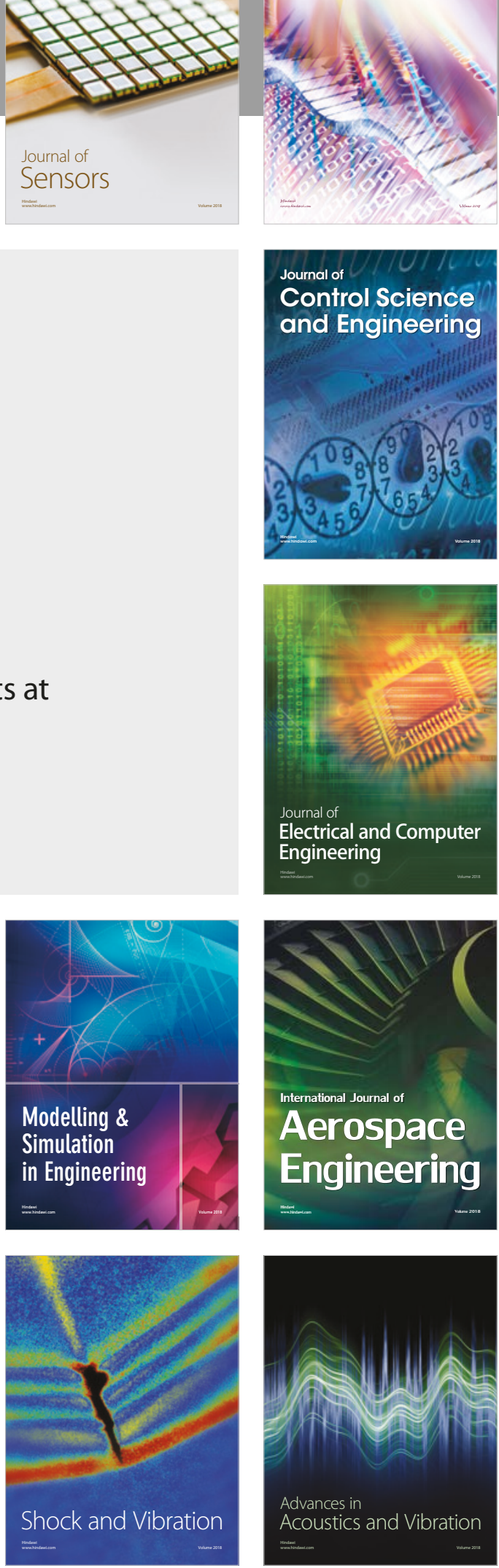